\title{
EDITORIAL
}

\section{A tribute to the past, and plans for the future: helping to drive top quality primary care respiratory disease management worldwide}

\author{
Paul Stephenson \\ Aziz Sheikh \\ Editors-in-Chief \\ Primary Care Respiratory Journal \\ Correspondence: \\ c/o The Primary Care Respiratory \\ Society UK \\ Smithy House, \\ Waterbeck, \\ Lockerbie, \\ DG11 3EY \\ UK \\ Tel: +44 (0)1461600639 \\ E-mails: \\ paul.stephenson@gp-d83012.nhs.uk \\ aziz.sheikh@ed.ac.uk
}

Received 10/2/11
The Primary Care Respiratory Journal (PCRJ) is the official journal of two organisations the Primary Care Respiratory Society UK (PCRS-UK) and the International Primary Care Respiratory Group (IPCRG). As a vehicle for disseminating primary care respiratory research, opinion and debate, and as a means of communicating with healthcare professionals involved in the care of patients with respiratory diseases, the $P C R J$ is very much the 'flagship' product of both societies. It is integral to their charitable work, and continues to drive up the standards of care for primary care patients with respiratory disease worldwide.

It is therefore a great honour and a privilege for us to take over as $P C R J$ Editors-in-Chief following the success of Dr Mark Levy's 15-year period in charge of the Journal. Though both of us have worked closely with him for most if not all of that time, ${ }^{1}$ the $P C R J$ is where it is today because of his ability, dedication, foresight, persistence, absolute academic integrity, and, when necessary, sheer stubbornness... Dr Levy's farewell editorial in the last issue ${ }^{2}$ should be essential reading for any aspiring journal editor. His description of the fear and trepidation he felt in 1996 as he embarked on the rocky journey to turn a society newsletter into a fully fledged academic journal, with the ever-present anxiety of how to obtain high quality manuscripts for publication - a struggle which eventually culminated in the awarding of full Medline/PubMed listing for the PCRJ in $2006^{3}$ - stands as an enormous tribute to him and a warning to anyone else tempted to do the same! He is very gracious in thanking those people who helped him along the way, ${ }^{2}$ but we all know that it was Mark Levy who was the leader, the figurehead, and the 'boss'. We take over as Editors-in-Chief of the PCRJ in the full knowledge that his 15-year tenure will be a supremely hard act to follow, but we are proud to follow in his footsteps and will do our utmost to preserve and develop his legacy.

The initial aims for the PCRJ as set out in 1996 have largely been met. The Journal currently stands firmly established as an international academic peer-reviewed journal for all those interested in respiratory medicine in primary care throughout the world, a role that is facilitated by free worldwide access to all PCRJ papers via the Journal website www.thepcrj.org. With a 2009 SCImago Journal Rank (SJR) of 0.182 and a 2-year citations per document index (broadly equivalent to the Thomson's Impact Factor) of $2.13^{4}$ (see Figure 1), this puts the $P C R J$ in the top $20 \%$ of all respiratory journals worldwide and one of only a handful of fully-indexed primary care journals.

By 2008, it was time to set out new aims for the Journal, and these were formulated in an International Editorial Board meeting held at the European Respiratory Society (ERS) Congress in Berlin that year. The PCRJ's two current aims are:

1. To provide an authoritative setting for the publication of high quality internationallyrelevant research that is essential to the future of primary care with specific regard to the care of patients with respiratory and respiratory-related allergic diseases

2. To inform and educate healthcare professionals worldwide of the research and service 


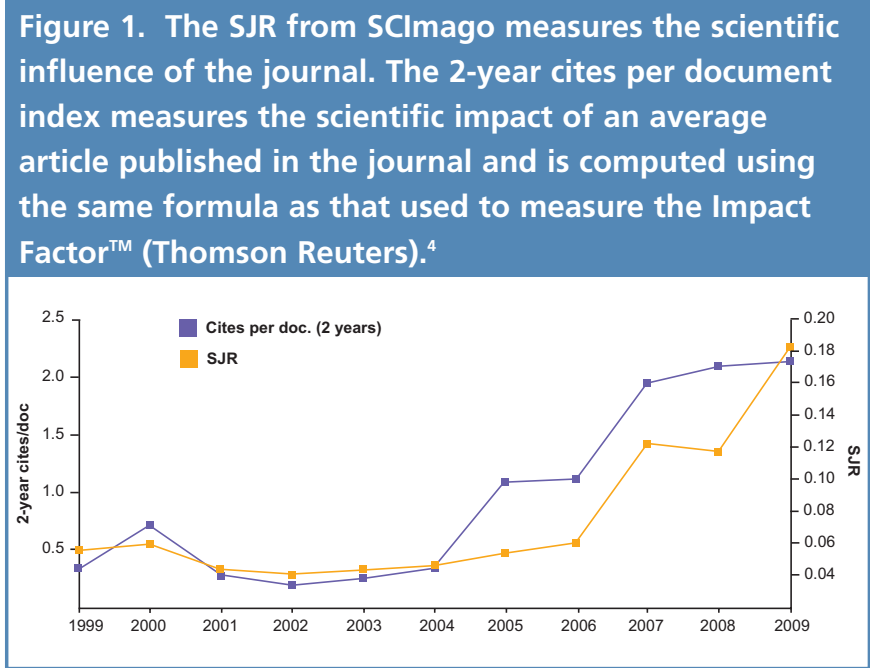

developments of relevance to primary care that promote excellence in their care of patients with respiratory and respiratory-related allergic diseases - and in so doing, to encourage young researchers, stimulate debate, drive consensus opinion, and to be a leader in the reporting of new concepts in the management of these patients.

Consequently, these aims set the parameters for our editorial strategy over this next three years. We seek to build on the excellent platform that already exists, and aim to develop the $P C R J$ into a truly top-tier international journal. In order to do this, we need to attract the very best author contributions from the best talent and resources available worldwide - contributions which have the greatest potential to impact on the care of patients across the globe. We believe this to be an eminently realistic target, as befits the standing of a Journal which represents two such important and wellrespected organisations internationally.

How will we do this? Firstly, manuscript submissions to the $P C R J$ are increasing year on year, and so we need to be much more selective in choosing papers for publication. We aim to pick the very best papers that have the potential to stand the test of time in a journal of record, and then work with authors and reviewers to improve those papers and disseminate them widely - by inviting commentaries from international authorities, and if necessary by developing a media strategy around particularly noteworthy papers that will help increase the awareness of key research findings. As Editors-in-Chief, we are now jointly assessing every manuscript within a week of submission and making an initial decision on whether to send it for peer review or to reject it straight away. If we cannot agree, we will seek a second opinion from one or both of our two Assistant Editors, Professors Chris Griffiths and Onno van Schayck. We will notify authors of this initial decision usually within a week but certainly within two weeks of submission. This will have two major benefits for authors. Those whose papers are rejected at this stage will at least know quickly and will be able to seek publication elsewhere - even though we know this decision will prove disappointing to many. But for those authors whose papers pass this initial hurdle, we will have a dedicated Handling Editor whose task will be to assess the paper again and seek the very best reviewers internationally with a view to improving the paper even further. These authors can be reassured that there is a fair likelihood their paper will eventually be published in the $P C R J$ after this robust critical review.

Secondly, for us to do justice to authors of top quality papers and provide a rapid peer review process, we need to strengthen our editorial team. One of the biggest challenges for any academic journal is how to acquire expert peer review for all those manuscripts that need it. One solution is to acquire some of that expertise inhouse. We have therefore just appointed 15 PCRJ Associate Editors, the successful candidates from a very high quality field of applicants. They will assist us in handling papers, and will contribute to a quick and efficient peer review process as well as helping us make decisions on paper acceptance. It is a formidable international list of mostly primary care respiratory researchers and clinicians, many of whom have key roles in the IPCRG and all of whom have a proven track record of providing high quality peer review:

Dr David Bellamy, Bournemouth, UK

Associate Professor Niels Chavannes, Leiden, The Netherlands Associate Professor Alan Crockett, Adelaide, Australia

Associate Professor Anthony D'Urzo, Toronto, Canada

Assistant Professor Maureen George, Philadelphia, USA

Ms Diane Goeman, Melbourne, Australia

Associate Professor Arnulf Langhammer, Levanger, Norway

Dr Gopal Netuveli, London, UK [Statistics Editor]

Dr Irem Patel, London, UK

Dr Hilary Pinnock, Edinburgh, UK

Dr Sundeep Salvi, Kalyaninagar, Pune, India

Associate Professor Tjard Schermer, Nijmegen, The Netherlands

Associate Professor Björn Ställberg, Uppsala, Sweden

Dr Mike Thomas, Aberdeen, UK

Dr Osman Yusuf, Islamabad, Pakistan

We are delighted that they have joined the PCRJ editorial team, and we look forward immensely to working with them.

Thirdly, and continuing the theme of in-house expertise, we have an outstanding International Editorial Board that contributes enormously to the academic credibility of the Journal. The Board members are incredibly generous of their time and expertise, either by reviewing papers, providing scientific and editorial expertise, adjudicating on editorial decisions, or contributing editorials or papers for publication. We are extremely grateful to them all. We are therefore very proud to announce the following new appointments to the Board:

Dr Liam Heaney, Belfast, N Ireland

Professor Jan Lötvall, Gothenburg, Sweden

Dr Lorcan McGarvey, Belfast, N Ireland

Dr Joan Soriano, Bunyola, Mallorca, Spain

Professor Wisia Wedzicha, London, UK 
In particular, we are also delighted to announce that Dr Mark Levy has accepted our invitation to remain on the Editorial Board as Editor Emeritus.

Fourthly, we will develop our fast-track service for papers that we consider to have exceptional importance. Historically, we have been able to get occasional selected papers copy-edited and typeset within 48 hours and published online within a week. We cannot promise to do this for every paper, but for fast-track papers we can certainly guarantee online publication within three weeks of acceptance. Therefore, if you are submitting a paper which you consider to have exceptional importance, please indicate this clearly in your covering letter, explaining the reason for the urgency; if we agree with your assessment we will do our utmost to process the paper as quickly as possible.

Of course, fifthly, we must not forget to encourage young researchers who are the lifeblood of the specialty. We continue to provide a vehicle for publishing pilot studies and shorter work via our Short Report section, and we are very pleased to receive Letters which inform the readership of exciting research findings that don't warrant a full-length paper publication. In addition, we will continue to provide an extensive copy-editing facility, which is of particular interest for authors whose first language is not English; if the quality of the science is good enough, we will endeavour to publish the paper even if the English prose needs a lot of attention. Also, as highlighted in our News section on page 105 , we are proud to announce that from this year there will be an annual PCRJ prize of $€ 500$ awarded to the best Abstract submitted to the ERS in the Primary Care Group category (Group 1.6), and the finished paper will be guaranteed publication in the PCRJ.

What does all this mean for our readers? We are firmly of the belief that the second of the Journal's two aims - to inform and educate primary healthcare professionals worldwide - is as important as the first. Readers should be reassured that we will be publishing top quality papers that will almost certainly have direct clinical relevance to the management of respiratory diseases in primary care. But in a busy world, with increasing demands on our time, not all readers have time to wade through the detailed text of Original Research papers - hence our desire to increase the number of editorials and commentaries in each issue of the Journal. Written by experts in that particular field, a good editorial puts a paper (or papers) into clinical context and provides an authoritative overview, often from an international perspective, which aids one's understanding of the message the authors are trying to convey. Those readers who have already sneaked a glance at the Contents list for this issue will see that it contains six editorials, and this is a trend that will continue...

How else can we increase the PCRJ's appeal to readers? Critical discussion and feedback are the bread-and-butter of scientific progress, and we are very keen to see this encouraged. We wish to receive correspondence ideally within six weeks of publication of a paper so that we can publish letters in the following issue, usually accompanied by a reply from the authors of the paper concerned. We also welcome suggestions on additional sections or types of contributions that you would like to see; we can't promise to deliver on all of these, but you can rest assured that all suggestions will be seriously considered. In the meantime, we will continue our Discussion paper and Research into Practice sections, both of which regularly contain articles that are highly relevant to the 'front line' clinician.

Finally, and perhaps most importantly for a Journal that is the official voice of the IPCRG, we are keen to increase dramatically the number of foreign language translations of $P C R J$ papers. If you - our global readership - would like to see a particular paper translated, we will work with the IPCRG and relevant partners to find the resources to obtain the highest standards of translation. Furthermore, we are aiming to develop the first of what we hope will be a number of foreign language Local Editions which will contain selected translated PCRJ papers of relevance to that country. Ours is a global Journal that needs to have an appropriate global presence, and this will facilitate that.

In the penultimate paragraph of his farewell editorial, ${ }^{2} \mathrm{Dr}$ Mark Levy highlighted the two major challenges now faced by the $P C R J$ - to move the Journal onto the next level as a source for the first line publication of internationally-relevant respiratory research, and to continue to satisfy the needs of 'grass roots' primary care clinicians in implementing and applying research findings in practice. We hope that these plans for the Journa/ will meet these two challenges. In so doing - with your help and support - the $P C R J$ will continue to help drive top quality primary care respiratory disease management throughout the world.

\section{References}

1. Levy ML, Stephenson P, Griffiths C, McKinley R, Sheikh A, Bryant P. The development of the Primary Care Respiratory Journal. Prim Care Respir J 2005; 14(3):120-1. http://dx.doi.org/10.1016/j.pcrj.2005.03.004

2. Levy ML. Farewell after 15 years. Prim Care Respir J 2010;19(4):299-300. http://dx.doi.org/10.4104/pcrj.2010.00080

3. Levy ML, Stephenson P, Griffiths C, et al. Primary Care Respiratory Journal is awarded full Medline/Index Medicus listing. Prim Care Respir J 2006;15(3):136-8. http://dx.doi.org/10.1016/j.pcrj.2006.04.003

4. http://www.scimagojr.com (Last accessed 28th January 2011)

Available online at http://www.thepcrj.org 